Published in final edited form as:

ACS Chem Biol. 2017 April 21; 12(4): 1075-1086. doi:10.1021/acschembio.7b00118.

\title{
Discovery and Characterization of a Potent and Specific Peptide Ligand Targeting Endothelial Progenitor Cells and Endothelial Cells for Tissue Regeneration
}

\author{
Dake Hao ${ }^{\dagger} \neq$, Wenwu Xiao§, Ruiwu Liu§, Priyadarsini Kumarł, Yuanpei Li§, Ping Zhou", \\ Fuzheng Guo ${ }^{\perp}$, Diana L. Farmer ${ }^{\ddagger}$, Kit S. Lam $\S$, Fengshan Wang ${ }^{*}, \dagger$, and Aijun Wang ${ }^{\star}, \ddagger$ \\ †Institute of Biochemical and Biotechnological Drug, School of Pharmaceutical Science, \\ Shandong University, Jinan, Shandong 250012, China \\ ¥Surgical Bioengineering Laboratory, Department of Surgery, School of Medicine, University of \\ California Davis, Sacramento, California 95817, United States \\ $\S$ Department of Biochemistry and Molecular Medicine, School of Medicine, University of California \\ Davis, Sacramento, California 95817, United States \\ "Institute for Regenerative Cures, University of California Davis Medical Center, Sacramento, \\ California 95817, United States \\ ${ }^{\perp}$ Institute for Pediatric Regenerative Medicine, Shriners Hospitals for Children, Sacramento, \\ California 95817, United States
}

\begin{abstract}
Endothelial progenitor cells (EPCs) and endothelial cells (ECs) play a vital role in endothelialization and vascularization for tissue regeneration. Various EPC/EC targeting biomolecules have been investigated to improve tissue regeneration with limited success often due to their limited functional specificity and structural stability. One-bead one-compound (OBOC) combinatorial technology is an ultrahigh throughput chemical library synthesis and screening method suitable for ligand discovery against a wide range of biological targets, such as integrins. In this study, using primary human EPCs/ECs as living probes, we identified an av $\beta 3$ integrin ligand LXW7 discovered by OBOC combinatorial technology as a potent and specific EPC/EC targeting ligand. LXW7 overcomes the major barriers of other functional biomolecules that have previously been used to improve vascularization for tissue regeneration and possesses optimal
\end{abstract}

\footnotetext{
*Corresponding Authors: School of Pharmaceutical Sciences, Shandong University, No. 44 Wenhuaxi Road, Jinan, Shandong 250012, China. Telephone: 86-531-88382589. fswang@ @du.edu.cn. Address: Department of Surgery, Surgical Bioengineering Laboratory, University of California Davis Health System, Research II, Suite 3005, 4625 Second Avenue, Sacramento, California 95817, USA. Telephone: 916-703-0422. aawang@ucdavis.edu.

Supporting Information

The Supporting Information is available free of charge on the ACS Publications website at DOI: 10.1021/acschembio.7b00118. Schematic illustration of the synthetic of LXW7-N3, effect of LXW7 removal on EPC proliferation, effect of LXW7 removal on EC proliferation, effect of LXW7 on expression of immature and mature endothelial markers, effect of LXW7 on Notch signaling pathway, and primers for qRT-PCR analysis (PDF)

ORCID

Aijun Wang: 0000-0002-2985-3627

Notes

The authors declare no competing financial interest.
} 
stability, EPC/EC specificity, and functionality. LXW7 is a disulfide cyclic octa-peptide (cGRGDdvc) containing unnatural amino acids flanking both sides of the main functional motif; therefore it will be more resistant to proteolysis and more stable in vivo compared to linear peptides and peptides consisting of only natural amino acids. Compared with the conventional av $\beta 3$ integrin ligand GRGD peptide, LXW7 showed stronger binding affinity to primary EPCs/ECs but weaker binding to platelets and no binding to THP-1 monocytes. In addition, ECs bound to the LXW7 treated culture surface exhibited enhanced biological functions such as proliferation, likely due to increased phosphorylation of VEGF receptor 2 (VEGF-R2) and activation of mitogen-activated protein kinase (MAPK) ERK1/2. Surface modification of electrospun microfibrous PLLA/PCL biomaterial scaffolds with LXW7 via Click chemistry resulted in significantly improved endothelial coverage. LXW7 and its derivatives hold great promise for EPC/EC recruitment and delivery and can be widely applied to functionalize various biological and medical materials to improve endothelialization and vascularization for tissue regeneration applications.

\section{Graphical abstract}

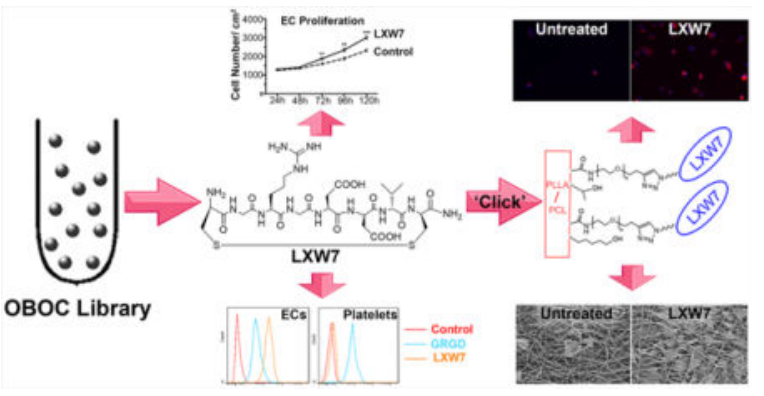

During past decades, tissue engineering has made considerable progress in the development of tissue substitutes and transplantable organs that maintain, restore, or improve host tissue functions. ${ }^{1}$ The potential impact of tissue engineering for changing human healthcare in the future is enormous. ${ }^{2}$ Endothelial progenitor cells (EPCs) and endothelial cells (ECs) play a vital role in vascularizing tissue engineered constructs for neotissue formation, long-term survival, and function. ${ }^{3,4}$ However, sufficient vascularization has been identified as a major challenge and a limiting factor for successful translation of tissue engineered products. ${ }^{5}$

Bioactive motifs on native extracellular matrices (ECM) are critical in providing cell-binding sites for cell and tissue adhesion, growth, and function. ${ }^{6,7}$ Biomaterial-based scaffolds are widely used in tissue engineering applications to provide a structural support for cells, either transplanted or recruited in situ, to attach, proliferate, and form a new vascular network. ${ }^{8,9}$ Synthetic materials can be precisely designed to mimic the physical structure of ECM via various sophisticated bioengineering approaches, but their applications are limited due to the lack of bioactive motifs that are present on native ECM. Creating a functional bioactive interface on the synthetic material to mimic a native ECM surface could significantly improve the biological functions of artificial scaffolds. ${ }^{10-12}$ Various functional biomolecules and strategies have been used to modify biomaterial-based scaffolds to improve endothelialization and vascularization in the scaffolds. ${ }^{4,13-18}$ However, most of these 
biomolecules are limited in translational application due to their unstable structure, nonspecific cell-binding affinity, and lack of the ability to functionally interact with ECs. Therefore, a potent, stable, bioactive molecule that can interact specially with EPCs/ECs but not with other undesirable ("off-target") cell types, such as platelets ${ }^{19-21}$ and inflammatory cells $^{22,23}$ that may cause detrimental body responses to the implanted scaffolds, is urgently needed for tissue engineering applications.

In the process of vascular development and regeneration, interactions between integrins, a family of heterodimeric receptors present on the cell surface, and their ligands in the ECM play important roles in vascular adhesion, migration, proliferation, survival, and differentiation. ${ }^{24,25}$ Previous reports showed that 16 integrins are involved in vascular biology, and eight of them are expressed on EPCs/ECs $(a 1 \beta 1, a 2 \beta 1, a 3 \beta 1, a 4 \beta 1, a 5 \beta 1$, $a 6 \beta 1, a v \beta 3$, and $a v \beta 5)$ at varying times. ${ }^{26,27}$ Thus, ligands that bind to integrins expressed on EPCs/ECs represent a good candidate for creating a bioactive interface to improve $\mathrm{EPC} / \mathrm{EC}$ attachment and vascularization. For example, the arginine-glycine-aspartic acid (RGD) motif is the most common integrin-binding sequence found within many ECM proteins and disintegrins. ${ }^{28-32}$ However, the conventional, native RGD sequences, such as GRGD, are not specific and can be recognized by different integrins. ${ }^{33}$ Therefore, there is a critical need to identify novel ligands to target specific integrins with high binding specificity and affinity for EPCs/ECs.

One-bead one-compound (OBOC) combinatorial technology is an ultrahigh throughput chemical library synthesis and screening method suitable for ligand discovery against a wide range of biological targets, such as integrins. ${ }^{34}$ Previously, we employed the OBOC combinatorial library method to discover cell attachment molecules and identified three potent ligands, LXY30, LXW7, and LLP2A, targeting integrin $a 3 \beta 1, a v \beta 3$, and $a 4 \beta 1$, respectively. ${ }^{35-37}$ All three of these integrins are highly expressed on the surface of EPCs/ ECs. In this study, to develop an optimal ligand with specific and high binding affinity to EPCs/ECs, we evaluated the interaction of these peptides with primary EPCs/ECs from different sources, platelets and monocytes; we found that LXW7 possessed the highest binding specificity to EPCs/ECs. ECs bound to an LXW7 treated culture surface exhibited enhanced biological functions such as proliferation, likely due to increased phosphorylation of VEGF receptor 2 (VEGF-R2) and activation of mitogen-activated protein kinase (MAPK) ERK1/2. We further established a protocol to immobilize LXW7 on the surface of biomaterial scaffolds via Click chemistry and proved the stability and functionality of LXW7 presented on the biomaterial surface. This study, for the first time, describes novel EPC/EC targeting bioactive ligands discovered by OBOC combinatorial library technology for tissue regeneration applications. The novel ligand LXW7 holds great promise to facilitate $\mathrm{EPC} / \mathrm{EC}$ attachment and function for improved endothelialization and vascularization of engineered tissue constructs. 


\section{RESULTS}

\section{Binding Affinity of Integrin-Targeting Peptide Ligands with EPCs/ECs Determined with On- Bead Whole Cell Binding Assay}

$a 3 \beta 1, a 4 \beta 1$, and $a \mathrm{v} \beta 3$ are functionally important integrins expressed on EPCs/ECs. ${ }^{26}$ Three integrin-targeting ligands LXY30 ( $a 3 \beta 1)$, LLP2A ( $a 4 \beta 1)$, and LXW7 ( $a$ v $\beta 3$ ) identified previously by the OBOC combinatorial library method ${ }^{35-37}$ were tested for their binding activities to EPCs/ECs. THP-1 monocytes play important roles in inflammation in the injured area and also express $a 4 \beta 1$ integrin. ${ }^{38}$ After $2 \mathrm{~h}$ of incubation, the results showed that LXY30 bound only to HCECs (Figure 1A,d), but not to HECFCs or to THP-1 monocytes (Figure 1A,a,g). LLP2A bound to both HECFCs and THP-1 monocytes (Figure 1A,b,h) but not to HCECs (Figure 1A,e). LXW7 bound both HECFCs and HCECs (Figure $1 \mathrm{~A}, \mathrm{c}, \mathrm{f}$ ) but not to THP-1 monocytes (Figure 1A,i). Quantification of the number of cells bound on each bead showed that there were significant differences between different types of cells bound on each bead modified with different types of ligands (Figure 1B). LXY30 only bound to ECs, not to EPCs. LLP2A only bound to EPCs, not to ECs. LXW7 bound to both EPCs and ECs well. On the basis of these results, we determined LXW7 as the optimal candidate ligand, and LXW7 was further characterized in the following experiments.

\section{Binding Specificity of LXW7 to EPCs/ECs}

Ligands with high binding specificity to EPCs/ECs not only support the rapid cell attachment but also potentially resist the attachment of other "off-target" cells, platelets, and proteins. To confirm binding specificity of LXW7 to EPCs/ECs, resin beads displaying LXW7 were incubated with EPCs/ECs from different sources (HECFCs, HCECs, and HMVECs), THP-1 monocytes, and platelets. At different time points after incubation (10 min, $30 \mathrm{~min}$, or $2 \mathrm{~h}$ ), phase contrast images were taken to determine cell-bead binding affinity. We found that LXW7 efficiently supported attachment of EPCs/ECs from different sources and the number of cells attached to LXW7 beads increased over time (Figure 2A, ai). Remarkably, LXW7 did not support effective attachment of THP-1 monocytes (Figure $2 \mathrm{~A}, \mathrm{j}-\mathrm{l}$ ) or platelets (Figure $2 \mathrm{~A}, \mathrm{~m}-\mathrm{O}$ ). Quantification of the number of cells/platelets bound on each bead showed that there were significantly more EPCs/ECs from different sources (HECFCs, HCECs, and HMVECs) compared to THP-1 monocytes and platelets on beads displaying LXW7 (Figure 2B). The results demonstrated that LXW7 possessed strong binding specificity to EPCs/ECs.

\section{Comparison of LXW7 with Conventional RGD Peptide on EPC/EC Binding Specificity and Affinity}

Conventional triamino acid sequence, arginine-glycine-aspartic acid, or "RGD" has been widely used as an adhesive peptide in the biomaterials field to improve cell attachment. However, conventional RGD binds to various types of cells and does not have high binding specificity to EPCs/ECs. ${ }^{39-41}$ To investigate whether LXW7 possess higher specificity to EPCs/ECs, we compared EC binding specificity and affinity of LXW7 with conventional GRGD peptide by flow cytometry. The results showed that LXW7 had higher binding affinity with different types of EPCs/ECs than conventional GRGD peptide (Figure 3C-E). Consistent with our previous results, both ligands did not bind to THP-1 monocytes (Figure 
3F), and LXW7 had very low binding affinity with platelets, but GRGD showed strong binding to platelets (Figure 3G), av $\beta 3$ integrin is the major integrin expressed on EPC/EC, 26,27 and $a \mathrm{IIb} \beta 3$ integrin is restricted to cells of the megakaryocyte lineage, such as platelets causing thrombosis in circulation. ${ }^{42,43}$ Therefore, to further investigate the binding selectivity of LXW7 and conventional GRGD peptide, we used $a v \beta 3-\mathrm{K} 562$ cells that highly expressed $a \mathrm{v} \beta 3$ integrin and $a \mathrm{IIb} \beta 3$-K562 cells that highly expressed $a \mathrm{IIb} \beta 3$ integrin as the probe cells to test the binding affinity of LXW7 and GRGD. We found that LXW7 had higher binding affinity than GRGD, although both GRGD and LXW7 bound well to av $\beta 3$ K562 cells (Figure $3 \mathrm{H}$ ). On the other hand, LXW7 showed very low binding to $a \mathrm{IIb} \beta 3$ K562 cells, whereas GRGD showed very strong binding (Figure 3I). These results demonstrated that LXW7 possessed higher binding affinity to $a v \beta 3$ integrin but lower binding affinity to $a \mathrm{IIb} \beta 3$ integrin than conventional RGD peptide, indicating that LXW7 has higher binding selectivity and superior potential than the conventional RGD peptide with respect to support stronger and more specific EPC/EC binding.

To confirm the results from the flow cytometry analysis, we employed live cell culture assays to determine cell-ligand binding affinity. We used LXW7-bio or GRGD-bio (D-biotin as the negative control) to treat the culture surfaces and investigated selective attachment of HCECs, THP-1 monocytes, and platelets on culture surfaces. HCECs bound to both LXW7 and GRGD treated surfaces within 10 min (Figure 4A,d,g) but not to the control surface (Figure 4A,a). The number of attached cells was quantified and showed that the LXW7 treated surface attracted more HCECs than the GRGD-modified surface (Figure 4B), further confirming that LXW7 outperforms GRGD in regards to binding with ECs. Additionally, both LXW7 and GRGD treated surfaces did not support THP-1 monocyte attachment similar to the control surface (Figure 4A,b,e,h and B). Furthermore, the LXW7 treated surface showed limited platelet adhesion, whereas the GRGD treated surface allowed a significantly higher number of platelets to attach (Figure 4A,f,i and B). This further confirmed our previous results that LXW7 supported stronger EC attachment but significantly weaker platelet attachment than conventional GRGD peptide.

\section{LXW7 Binds to EPCs and ECs via av $\beta 3$ Integrin}

av $\beta 3$ integrin is highly expressed on EPCs and ECs. ${ }^{26,27}$ To further confirm that LXW7 binds to EPCs/ECs mainly via av $\beta 3$ integrin, we performed a binding/blocking experiment using a monoclonal anti- $a v \beta 3$ integrin antibody. The results showed $a v \beta 3$ integrin was highly expressed on HECFCs (Figure 5A, 99.0\%), HCECs (Figure 5B, 100\%), and HMVECs (Figure 5C, 97.3\%). For the binding/blocking experiment, the results showed LXW7 had high binding efficiencies to EPCs and ECs, and the binding efficiencies of LXW7 to EPCs/ECs were all significantly blocked by the anti- $\alpha \mathrm{v} \beta 3$ integrin antibody at 20 $\mu \mathrm{g} / \mathrm{mL}$ (Figure 5D-F). These data indicate that the binding of LXW7 to EPCs and ECs is mainly mediated by $a v \beta 3$ integrin.

\section{Effects of LXW7 on EC Biological Functions}

We confirmed that LXW7 supported effective EC attachment. To determine whether LXW7 has any effects on other biological functions of ECs, we tested the effects of LXW7 on key functions of vascularization. The effect of LXW7 on EC proliferation was tested by MTS 
assay at different time points. Results showed that the LXW7 treated surface significantly promoted EC proliferation after $48 \mathrm{~h}$ in culture compared with the D-biotin treated surface (control), and this trend was maintained for the entire period of the experiment (Figure 6A). We also tested whether the EPC/EC proliferation will be changed after LXW7 removal. EPCs (HECFCs) and ECs (HCECs) were first cultured on surface modified with or without LXW7 for 4 days, and then cells were lifted, and $3 \times 10^{3}$ viable cells were seeded per well in regular 96-well plates and cultured in EGM-2 media for 5 days. MTS assay was performed each day and analyzed. The results showed that the proliferation of EPCs and ECs that were temporarily cultured on the LXW7 modified surface did not change after LXW7 removal (Figures S2 and S3). These results indicated that persistent LXW7 existence was necessary to maintain the relevant bioactivities of EPCs/ECs, such as proliferation. ECs cultured on the LXW7 treated surface for $96 \mathrm{~h}$ were collected for Western-blot analysis. Compared with the D-biotin treated surface (control), the LXW7 treated surface significantly increased the phosphorylation of VEGFR2 (Tyr1175) and phosphorylation of its downstream signaling molecule ERK1/2 in ECs (Figure 6B). Our results were consistent with previous studies showing that activation of integrin $a v \beta 3$ increased phosphorylation of VEGFR2 and ERK1/2 and promoted EC proliferation. ${ }^{44,45}$ LXW7 induced EC proliferation may be attributed to the fact that LXW7 activated $a v \beta 3$ integrin and therefore enhanced phosphorylation of VEGFR2 and ERK1/2 and induced EC proliferation. On the other hand, integrins have also been demonstrated to play a role in stem cell differentiation. ${ }^{46}$ The Notch signaling pathway has been shown to promote vascular maturation, ${ }^{47}$ even by inducing integrin-mediated cell adhesion to the endothelial basement membrane. ${ }^{48}$ We further tested the effect of LXW7 on the expression of immature and mature endothelial markers and Notch signaling pathway genes. The qPCR results showed no significant difference in the expression of these genes (Figures S4 and S5), indicating that LXW7 did not change the expression of endothelial markers and Notch signaling pathway genes in EPCs/ECs.

\section{Biomaterial Scaffold Surface Modified with LXW7 Supported EC Attachment and Spreading}

ECM provides a three-dimensional structure and native ligands for cell attachment and tissue growth and function. ${ }^{49}$ To mimic ECM structure, we employed electrospinning technology to produce microfibrous scaffolds using PLLA and PCL polymer blends. SEM images showed that the electrospun scaffolds had a porous structure of microfibers (Figure 7A), similar in morphology to the native ECM. These scaffolds have a disadvantage over the ECM in that they lack bioactive motifs such as the integrin ligands that are normally present on the ECM and hence modification of the artificial ECM with functional ligands could improve its biological functions. Our prior results have suggested that LXW7, an artificial ligand targeting av $\beta 3$ integrin that can bind specifically to EPCs/ECs and activate EC biological functions, would be a good choice to modify the biomaterial scaffold surface. To improve biological functions of the microfibrous scaffolds, we developed a protocol to functionalize the polymer surface by LXW7 via Click chemistry (Figure 7C). LXW7 was first functionalized with an azido group (Figure 7B). Microfibrous membranes were functionalized by covalently attaching $\mathrm{H}_{2} \mathrm{~N}-\mathrm{PEG}$-alkyne to the carboxylic groups on the microfibers using EDC and Sulfo-NHS (Figure 7C). LXW7- $\mathrm{N}_{3}$ was then attached to $\mathrm{H}_{2} \mathrm{~N}$ PEG-alkyne functionalized microfibers by Click chemistry (Figure 7C). ATR-FTIR 
spectrum analysis which has been proven to be a powerful tool for detecting amide bonds on solid surfaces ${ }^{50}$ was used in this study to determine the immobilization of LXW7 on the scaffold surface. The ATR-FTIR spectra of the untreated and modified surfaces are shown in Figure 7D. The typical spectrum of the membranes modified with PEG-LXW7 was represented by an obvious rise in the intensity of the peak attributed to the amide I groups $\left(1647 \mathrm{~cm}^{-1}\right.$ ), which were distributed in a large number in the structure of LXW7-N 3 (Figure 7B). The spectrum of the membranes modified by PEG showed only a small evolution around 1630 and $1670 \mathrm{~cm}^{-1}$ compared to the spectrum of the untreated membrane, because only a few amide I groups were formed after the membranes were modified with PEG linker only (Figure 7C). There was a significant difference between the spectra of PEG-LXW7 and PEG only modified membranes at $1647 \mathrm{~cm}^{-1}$, indicating that a large amount of amide I groups were introduced onto the membrane after LXW7 was modified (Figure 7D). All these data confirmed that LXW7 had been successfully immobilized on the membrane surface.

\section{EC Attachment and Spreading on Biomaterial Surface Modified with LXW7}

To determine whether LXW7 can be used for biomaterial surface modification and whether the LXW7 modified biomaterial surface can support EC attachment and growth, HCECs were seeded on PLLA/PCL microfibrous membranes modified with or without LXW7 and cultured in EGM-2 media for $2 \mathrm{~h}$. After washing, HCECs attached on an untreated membrane (Figure 8A,a) and a LXW7 modified membrane (Figure 8A,b) were fixed and stained with CD31 antibody. Quantification of CD31 positive cells showed that there were significantly more HCECs adhered to LXW7-modified membranes compared to untreated membranes (Figure 8B). HCECs adhered on the membrane surfaces at $2 \mathrm{~h}$ were kept in culture for 2 days. SEM analysis showed that ECs grew and spread much better on an LXW7-modified membrane (Figure 8C,b,d) compared to the untreated membrane (Figure $8 \mathrm{C}, \mathrm{a}, \mathrm{c})$. Quantification of cell-covered area showed that there was significantly more cellcovered area on LXW7-modified membranes compared to untreated membranes (Figure 8D). These results demonstrated that the function of LXW7 was well maintained after chemical modification, and LXW7-modified biomaterials supported excellent attachment and spreading of ECs.

\section{DISCUSSION}

Tissue engineering, a fast growing field in regenerative medicine, has shown significant prominence over the past three decades. ${ }^{51}$ Vascularization is critically central to tissue development, maintenance, and regeneration. ${ }^{52}$ EPCs and ECs from different sources, such as circulation and local tissues, play crucial roles in the process of vascularization. ${ }^{53,54} \mathrm{In}$ addition, bioactive coating or modification of biomaterial scaffolds hold the promise of improving tissue regeneration by stimulating the formation of necessary blood vessels required for the short-term tissue regeneration and long-term tissue survival and function. ${ }^{55}$ Therefore, an ideal bioactive coating molecule that specifically targets EPCs/ECs can be used for biomaterial engineering to achieve functional and meaningful tissue regeneration. Several important aspects need to be taken into account for choosing bioactive molecules: (1) having high binding specificity to EPCs/ECs and not to other undesirable cell types to 
improve endothelialization and vascularization, reduce inflammation, and prevent thrombosis; (2) displaying all high-extended bioactive functionality after modification to ECs; and (3) possessing good stability and low degradation in the body.

The understanding of the intricate interactions between cells and their microenvironment ECM in tissues has been much improved in past decades. Attributed to basic biological understanding, more attention in the field of tissue engineering has been focused on the designing of optimal scaffolds that can imitate the componential and structural aspects of ECM to facilitate cell recruiting/seeding, adhesion, proliferation, differentiation, and neotissue genesis. ${ }^{56-58}$

From a structural perspective, natural ECM consists of various interwoven protein fibers with diameters ranging from nanometers to micrometers. The nano/microscale structure of ECM offers a natural network of nanofibers to support and guide cell behavior and function. Developing scaffolds that imitate the architecture of ECM is an effective approach to improving the functionality of the scaffolds. The electrospinning technique is a powerful tool to make nano/microfibrous scaffolds that imitate the native tissue architecture, allow the integration of the grafts/scaffolds with surrounding cells, and promote tissue regeneration. We have successfully used electrospinning techniques to fabricate microfibrous scaffolds for various tissue regeneration applications such as for peripheral nerve regeneration, ${ }^{59,60}$ spinal cord regeneration, ${ }^{61-64}$ vascular tissue regeneration, ${ }^{15}$ drug delivery, ${ }^{65}$ and wound healing. ${ }^{66}$

From a componential perspective, natural ECM consists of a wide variety of biomolecules that provide critical biological binding sites for the cells to function in a specific way. Ordinary electrospun microfibrous scaffolds have the three-dimensional structure imitating the native ECM architecture but lack bioactive molecules on the surface. Therefore, their functionalities can be further improved by modifying their surface with bioactive ligands.

The OBOC combinatorial library method is a powerful tool to identify ligands with high specificity and affinity to a desired cell type. It is known that RGD can be recognized by nearly half of the over 20 integrins including $a \mathrm{v} \beta 3$ and $a \mathrm{IIb} \beta 3$, and the binding specificity of different RGD-containing peptides to different integrins depends on the conformation structure of the RGD motif and the adjacent amino acids of the ligand. ${ }^{67}$ The OBOC library can be designed based on the main triad motif flanking with random amino acids leading to the discovery of specific ligands with higher affinity and selectivity toward targeted cells. In addition, non-natural amino acids and disulfide bonds with D-cysteines are chosen to synthesize the ligands with higher stability in vivo. ${ }^{36}$ In recent years, we have used this technology and identified several important ligands targeting different cell surface integrin receptors. ${ }^{35,37,68,69}$ av $\beta 3$ integrin is highly expressed on angiogenic ECs and EPCs, and hence ligands specifically targeting the $a \mathrm{v} \beta 3$ integrin would have significant application for tissue engineering and regeneration where EC behavior and functions are critically needed.

Previously, we confirmed that LXW7, a peptide discovered by screening OBOC libraries, had high binding affinity to $a \mathrm{v} \beta 3$ integrin $\left(K_{\mathrm{d}}=76 \pm 10 \mathrm{nM}, \mathrm{IC}_{50}=0.68 \pm 0.08 \mu \mathrm{M}\right){ }^{36} \mathrm{In}$ the present study, we further investigated the binding specificity and functionality of LXW7 to EPCs and ECs. Conventional RGD-containing peptides derived from native ECM 
sequences have been reported to bind to $a \mathrm{v} \beta 3$ integrin, ${ }^{36,40}$ but they had low binding specificity to EPCs/ECs. ${ }^{70}$ Our data in the present study showed that LXW7 exhibited higher binding affinity to EPCs and ECs isolated from various sources compared with the conventional GRGD sequence. More importantly, we found that LXW7 did not bind to monocytes and showed very low binding affinity to platelets. Monocytes can be attracted and accumulate at sites of inflammation and infections and cause detrimental body responses such as forming early plaques in vascular diseases by differentiating into foam cells. ${ }^{71}$ It is known that $\beta 1$ integrins, especially $a 4 \beta 1$, are highly expressed on monocytes and mainly responsible for extracellular matrix protein binding in monocytes, but $\beta 3$ integrins are not expressed on monocytes, ${ }^{72,73}$ and these may explain why LXW7 does not bind to monocytes. Platelets easily aggregate in blood and deposit on the vascular bed and secrete numerous proteins that promote attachment of the other cells that carry a deleterious risk of thrombus formation. Therefore, the adhesion and activation of platelets and inflammatory cells on the material surface is often used to evaluate a material's thrombogenicity. ${ }^{21,74-76}$ It is known that the adhesion and aggregation of platelets are mediated by $a \operatorname{IIb} \beta 3$ integrin rather than $a \mathrm{v} \beta 3$ integrin, ${ }^{42}$ and this explains why LXW7 showed very low binding affinity to platelets. These indicate that LXW7 might be a better ligand for EPC/EC recruitment and delivery applications. From the antibody binding/ blocking experiments, we confirmed that the interaction between LXW7 and EPCs/ECs is mainly mediated by $a v \beta 3$ integrin. We also noted that the binding of LXW7 to EPCs/ECs was not completely blocked by anti-av $\beta 3$ integrin antibody, probably due to the size difference between LXW7 (a short peptide of eight amino acids) and anti- $a \mathrm{v} \beta 3$ integrin antibody, which is a large biomacromolecule. LXW7 also improved EC proliferation and increased phosphorylation of VEGFR2 and ERK1/2 in ECs. This is consistent with the results in the previous studies about the interaction between $a \mathrm{v} \beta 3$ integrin and VEGFR2 and ERK1/2 in ECs. ${ }^{44,45,77}$ Although LXW7 was originally discovered through screening a focused cyclic RGD library with engineered myeloid leukemia K562 cells, we can easily use EPCs/ECs as probes to screen similar libraries. Furthermore, in addition to just screening for cell binding, we can easily screen for both binding and cell signaling such as ERK1/2 activation. The latter can be achieved via staining the bound cells with antiphospho-ERK1/2 antibody followed by secondary antibody-horse radish peroxidase and colorimetric substrate.

From another crucial angle, the addition of tool molecules, such as biotin, to ligands will be advantageous when used in combination with other components and to expand the ligand's bioengineering applications. Our previous study has shown that biotinylation of LXW7 did not decrease its binding affinity and showed nearly identical binding strength to $a v \beta 3$ integrin, ${ }^{36}$ whereas biotinylation of commonly used pentapeptides, such as cyclo(RGDfE), cyclo(RGDfK), and cyclo(RGDyK) lead to a 2-to 8-fold decrease in the affinity strength to av $\beta 3$ integrin. ${ }^{36}$ In this study, we designed LXW7-N3, and utilized Click chemistry to immobilize LXW7-N3 on the electrospun microfibrous PLLA/PCL membrane surface. In order to minimize the effect of the linker to the ligand binding and increase its water solubility, two units of PEG-like short linker (Ebes) were inserted between the C-terminus of the ligand and Lys (biotin) as well as Click conjugation site $\left(\mathrm{N}_{3}\right)$. We have successfully used the same linker strategy in many of our previous ligand conjugates. ${ }^{78,79}$ The LXW7 
modified surface significantly increased the binding of ECs to the scaffold surface and improved endothelial coverage on the material surface. LXW7 is a potent ligand for surface modification of tissue engineered biomaterial constructs to improve endothelial coverage and vascularization in the scaffolds. We plan on utilizing this approach for in vitro EC expansion and in vivo delivery for 3D biomaterial scaffold surface modification to improve in situ $\mathrm{EC}$ recruitment, endothelialization, and vascularization. We also plan on testing the in vivo efficacy of LXW7 to modify vascular grafts to improve endothelialization for blood vessel regeneration.

\section{Conclusion}

In this study, we discovered that a novel $a v \beta 3$ integrin ligand LXW7 can potential be widely used for tissue engineering applications. Unlike the traditional integrin $a v \beta 3$ ligand GRGD peptide, LXW7 showed highly specific and strong interaction with EPCs/ECs but did not bind to monocytes and had very low binding affinity to platelets. Therefore, LXW7 can be used as an excellent EC specific ligand to improve EC biological functions while preventing platelet and inflammatory cell adhesion. LXW7 is a cyclic peptide containing natural and non-natural amino acids; therefore it will be more resistant to proteolysis and more stable in vivo compared to linear peptides only consisting of natural amino acids. Furthermore, LXW7 can be used as an excellent lead ligand for further optimization by using the high throughput $\mathrm{OBOC}$ focused combinatorial library to develop more potent and specific small bioactive ligands that could be used in the future for more specific tissue regeneration applications.

\section{MATERIALS AND METHODS}

\section{Cell Culture and Platelet Isolation}

Endothelial colony forming cells (ECFCs), also often referred to as outgrowth endothelial cells (OECs), which are a subtype of EPCs, can be identified from circulating human adult peripheral blood and umbilical cord blood. ${ }^{80}$ In this study, the ECFCs were isolated from human umbilical cord blood as previously described. ${ }^{80,81}$ Human umbilical cord blood (10 $\mathrm{U}$ heparin/mL blood) was obtained from the UC Davis Umbilical Cord Blood Collection Program (UCBCP) and diluted 1:1 with phosphate-buffered saline (PBS), without calcium and magnesium, pH 7.2 (Hyclone). A total of $15 \mathrm{~mL}$ of Ficoll-Paque PLUS (Amersham Biosciences) was laid at the bottom of $20 \mathrm{~mL}$ of diluted blood and centrifuged at $2000 \mathrm{rpm}$ for $30 \mathrm{~min}$ at RT. The hazy layer of mononuclear cells (MNCs) at the interface between the Ficoll and serum was collected and dispensed into a $50 \mathrm{~mL}$ conical tube containing $10 \mathrm{~mL}$ of EBM-2 (Lonza) and centrifuged at $1500 \mathrm{rpm}$ for $10 \mathrm{~min}$ at RT. The supernatant was carefully aspirated, and the pellets were treated with red blood cell lysis buffer (eBioscience, Inc.) and then sorted by $\mathrm{CD} 34$ microbead magnetic sorting (Miltenyi Biotec $\mathrm{GmbH}$ ) as per the manufacturer's instructions. The $\mathrm{CD} 34^{+}$cells were seeded on rat-tail collagen I (BD Biosciences Discovery) coated tissue culture plates and cultured in EGM-2 media (Lonza). After $24 \mathrm{~h}$, nonadherent cells were removed, and the media were changed daily to day 7 and every other day thereafter. ECFC-derived colonies appeared between day 4 and day 7 of culture with a typical endothelial cobblestone pattern. Individual colonies were isolated and expanded and allowed to grow to $80 \%$ to $90 \%$ confluency before first passage. ECFCs were 
used between P3 and P5 for all experiments. Human coronary artery endothelial cells (HCECs) were purchased from ATCC. Human cardiac microvascular endothelial cells (HMVECs) were purchased from Lonza. THP-1 monocytes were obtained from Dr. Pamela Lein (University of California, Davis). The myeloid leukemia K562 cells that have been transfected with the human integrin $a v \beta 3$ gene ( $\alpha \mathrm{v} \beta 3-\mathrm{K} 562$ cells) were provided by Dr. Yoshikazu Takada, and the K562 cells transfected with human integrin $a \mathrm{IIb} \beta 3$ gene ( $\mathrm{IIIb} \beta 3$-K562 cells) were provided Dr. Jennifer Cochran (Stanford University)

HECFCs, HCECs, and HMVECs were cultured in EC expansion medium EGM-2, and THP-1 monocytes were cultured in RPMI Medium 1640 (Gibco) supplemented with 10\% fetal bovine serum (FBS, Hyclone) and 0.05 mM 2-mercaptoethanol (Sigma). av $\beta 3$-K562 cells and $a \mathrm{IIb} \beta 3-\mathrm{K} 562$ cells were cultured in RPMI Medium 1640 plus $10 \%$ FBS. Plateletrich plasma (PRP) was obtained from UC Davis Medical Center (Sacramento, CA). Fresh PRP $\left(260 \times 10^{3}\right.$ platelets $\left./ \mu \mathrm{L}\right)$ was centrifuged, and the pellets were resuspended in DPBS (Hyclone) containing $2 \mathrm{mM} \mathrm{CaCl}_{2}$ and $1 \mathrm{mM} \mathrm{MgCl}_{2}$ to a final concentration of $1 \times 10^{8}$ platelets/mL prior to use.

\section{Synthesis and Screening of OBOC Peptide Libraries}

In our previous studies, we synthesized and screened several random linear and cyclic OBOC peptide libraries using a cell-growth-on-bead assay and identified three potent ligands LXY30, LXW7, and LLP2A targeting integrin $a 3 \beta 1, a v \beta 3$, and $a 4 \beta 1,{ }^{35-37}$ respectively. All of these integrins are highly expressed on the surface of EPCs/ECs. In this study, we synthesized LXY30, LXW7, and LLP2A on TentaGel resin beads and used them as a convenient platform for cell-bead and platelet-bead binding assays to investigate the ligand-cell/platelet binding affinity and specificity.

\section{EPC/EC-Bead, Monocyte-Bead, and Platelet-Bead Binding Assay}

HECFCs, HCECs, HMVECs, and THP-1 monocytes were cultured in their respective growth media described above. For the cell bead-binding assay, $6 \times 10^{5}$ HECFCs, HCECs, HMVECs, or THP-1 monocytes in $2 \mathrm{~mL}$ of their respective culture medium were added to an ultralow attachment $35 \mathrm{~mm}$ Petri dish (Corning Incorporated) followed by resin beads. ${ }^{34}$ The dishes were incubated in a shaking incubator at $37{ }^{\circ} \mathrm{C}$ and $5 \% \mathrm{CO}_{2}$ for various time points at $40 \mathrm{rpm}$. For platelet-bead binding assay, the platelets isolated as described above were added to an ultralow attachment $35 \mathrm{~mm}$ Petri dish and incubated with the resin beads in the shaking incubator as described for the cell-bead binding assay. Phase contrast images were taken at different time points using Olympus IX81microscope.

\section{Flow Cytometry Analysis of Ligand-Cell Binding Affinity}

We synthesized biotinylated LXW7 (LXW7-bio, Figure 3A) and biotinylated GRGD (GRGD-bio, Figure 3B) using established solid phase peptide synthesis protocols. ${ }^{36}$ Peptidebio was designed to have biotin attached to the side chain of Lys, and two hydrophilic linkers between peptide and Lys (biotin). To quantitatively compare cell-ligand binding affinity, flow cytometry analysis of LXW7-bio and GRGD-bio (D-biotin as negative control) with EPCs, ECs, THP-1 monocytes, and platelets as well as integrin overexpressing K562 cell lines was performed. Specifically, $3 \times 10^{5}$ HECFCs, HCECs, HMVECs, av $\beta 3$-K562 
cells, $a \mathrm{IIb} \beta 3$-K562 cells, THP- 1 monocytes, or $1 \times 10^{8}$ platelets were incubated with LXW7-bio $(1 \mu \mathrm{M})$ in binding buffer (1× HEPES containing 10\% FBS) on ice for $30 \mathrm{~min}$. The samples were washed three times with wash buffer (DPBS containing 1\% FBS) and incubated with $2 \mu \mathrm{g} / \mathrm{mL}$ of streptavidin-phycoerythrin on ice for $30 \mathrm{~min}$ and then washed with DPBS. To test the expression of the av $\beta 3$ integrin on HECFCs, HCECs, and HMVECs, samples were stained with $20 \mu \mathrm{g} / \mathrm{mL}$ mouse antihuman $a \mathrm{v} \beta 3$ integrin antibody (Abcam) on ice for $30 \mathrm{~min}$, washed three times with wash buffer, and incubated with goat antimouse 488 conjugate (1:100; Abcam) in DPBS on ice for $30 \mathrm{~min}$ and then washed with DPBS. To confirm that LXW7 binds to EPCs/ECs mainly via av $\beta 3$ integrin, we performed a binding/ blocking experiment using a monoclonal anti- $a \mathrm{v} \beta 3$ antibody. To block $a \mathrm{v} \beta 3$ integrin, cells were first incubated with $20 \mu \mathrm{g} / \mathrm{mL}$ mouse antihuman $a \mathrm{v} \beta 3$ integrin antibody (Abcam) on ice for $30 \mathrm{~min}$, washed three times with wash buffer, and then incubated with LXW7-bio (1 $\mu \mathrm{M})$ for another $30 \mathrm{~min}$. The samples were washed three times with wash buffer and incubated with premixed goat antimouse 488 conjugate (1:500; Life Technologies) and 2 $\mu \mathrm{g} / \mathrm{mL}$ Streptavidin PE-Cy7 conjugate (Life Technologies) in DPBS on ice for $30 \mathrm{~min}$ and then washed with DPBS. Samples were analyzed on a BD Fortessa LSR Cell Analyzer, and further data analysis and gating were performed using FlowJo software (Treestar, Inc.).

\section{EC, Monocyte, and Platelet Attachment Assay}

To modify the culture surface with ligands, target culture wells in a 24-well plate were coated with $500 \mu \mathrm{L}$ of $20 \mu \mathrm{g} / \mathrm{mL}$ Avidin (Thermo Fisher Scientific) and incubated for $1 \mathrm{~h}$ at $37^{\circ} \mathrm{C}$. Avidin coated wells were rinsed three times with DPBS and were treated with $500 \mu \mathrm{L}$ molar equivalents ( $2 \mu \mathrm{M})$ of D-biotin (Thermo Fisher Scientific), LXW7-bio, or GRGD-bio. After $1 \mathrm{~h}$, the wells were washed three times with DPBS and blocked with 1\% BSA (Thermo Fisher Scientific) for $1 \mathrm{~h}$. After the wells were rinsed three times with DPBS, for the cell attachment assay, $5 \times 10^{4}$ HCECs and THP- 1 monocytes suspended in the respective maintenance medium were added to the wells and incubated for $10 \mathrm{~min}$ or $16 \mathrm{~h}$ at $37{ }^{\circ} \mathrm{C}$ and $5 \% \mathrm{CO}_{2}$, respectively. After each time point the wells were washed three times with DPBS, and the adhered cells were fixed in 10\% formalin (Azer Scientific) for $20 \mathrm{~min}$. For platelet attachment assay, the PRP was centrifuged, and the platelet pellet was resuspended in $1 \%$ BSA with $2 \mathrm{mM} \mathrm{CaCl}_{2}$ and $1 \mathrm{mM} \mathrm{MgCl} \mathrm{m}_{2}$ to achieve a final concentration of $1 \times 10^{8}$ platelets $/ \mathrm{mL}$ and added to the wells at a density of $5 \times 10^{7}$ platelets $/ \mathrm{cm}^{2}$ and incubated for $16 \mathrm{~h}$ at $37{ }^{\circ} \mathrm{C}$ and $5 \% \mathrm{CO}_{2}$. The wells were washed three times with DPBS, and the adhered platelets were fixed in $10 \%$ formalin for $20 \mathrm{~min}$. For evaluation of HCEC attachment, the HCEC wells were washed with DPBS again and blocked for $1 \mathrm{~h}$ with $1 \%$ BSA. An additional wash was performed, and the plate was incubated overnight with mouse antiCD31 antibody (1:100; Abcam) in $1 \%$ BSA at $4{ }^{\circ} \mathrm{C}$. The wells were washed and incubated with goat antimouse Alexa Fluor 594 conjugate (1:500; Life Technologies) in 1\% BSA for 1 $\mathrm{h}$ at RT, and then nuclei were stained with DAPI. After three washings with DPBS, the HCECs were imaged using an Olympus IX81 microscope. Phase contrast images were taken using an Olympus IX81microscope for evaluation of the THP-1 monocyte and platelet attachment. Quantification of images was performed using the ImageJ software (NIH). 


\section{MTS Assay of EC Proliferation on LXW7}

The 96-well plates were treated with $1 \mu \mathrm{M}$ Avidin solution for $1 \mathrm{~h}$ at RT. Avidin coated wells were rinsed three times with DPBS and treated with LXW7-bio $(1 \mu \mathrm{M})$, with D-biotin (1 $\mu \mathrm{M}$ ) serving as the control. After $1 \mathrm{~h}$, the wells were washed three times with DPBS and blocked with $1 \%$ BSA for $1 \mathrm{~h}$. A total of $3 \times 10^{3}$ viable HCECs were seeded per well and cultured in EGM-2 media for 5 days. To test whether the EPC/EC proliferation will be changed after LXW7 removal, we first cultured EPCs (HECFCs) and ECs (HCECs) on a culture surface modified with or without LXW7 for 4 days. Then, EPCs/ECs were lifted from the culture surface modified with or without LXW7, and $3 \times 10^{3}$ viable cells were seeded per well in 96-well plates and cultured in EGM-2 media for 5 days. An MTS assay was performed at each day per the manufacturer's instructions (Interchim) and analyzed on a SpectraMax-3 plate reader (Molecular Devices).

\section{Western-Blot Analysis}

The $100 \mathrm{~mm}$ dishes were first treated with Avidin followed by LXW7-bio or D-biotin as described above. A total of $8 \times 10^{5}$ HCECs were seeded per dish and cultured in EGM-2 media for 4 days. Cells were lysed using an extraction kit (Thermo Fisher Scientific), and protein concentrations were determined using a BCA protein assay (Thermo Fisher Scientific). A total of $15 \mu \mathrm{g}$ of each sample was loaded and separated using a 4-12\% BisTris NuPAGE gel (Thermo Fisher Scientific) and transferred to a nitrocellulose membrane. The membrane was blocked in 5\% BSA in TBST (Tris-buffered saline with 0.5\% Tween-20) and subsequently incubated with primary antibodies anti-VEGF Receptor 2, anti-PhosphoVEGF Receptor 2, anti-p44/42 MAPK (ERK1/2), and anti-Phospho-p44/42 MAPK (ERK1/2) (Thr202/Tyr204), all purchased from Cell Signaling Technologies, in 1\% BSA overnight at $4{ }^{\circ} \mathrm{C}$. After washing three times with TBST, the membranes were incubated with respective horseradish peroxidase-conjugated secondary antibodies in $1 \%$ nonfat dry milk in TBST (BioRad) for $1 \mathrm{~h}$ at RT. After washing, the protein bands were visualized using a West Dura substrate (Thermo Fisher Scientific) and quantified using ImageJ software.

\section{Real-Time Quantitative RT-PCR (RT-qPCR)}

The $60 \mathrm{~mm}$ dishes were first treated with Avidin followed by LXW7-bio or D-biotin as described above. A total of $1.5 \times 10^{6}$ HECFCs or HCECs were seeded per dish and cultured in EGM-2 media for $24 \mathrm{~h}$. Total RNA was extracted from cells using RNeasy Plus Mini Kit (Qiagen). DEPC-treated water, dNTP mix, random hexamer, DTT, RNaseOUT, FS buffer, and superscript II (all from Invitrogen) were used for cDNA synthesis. The PCR conditions for all genes were as follows: $48{ }^{\circ} \mathrm{C}$ for $30 \mathrm{~min}$ and then $95{ }^{\circ} \mathrm{C}$ for $10 \mathrm{~min}$ followed by 40 cycles of $95{ }^{\circ} \mathrm{C}$ for $30 \mathrm{~s}, 58{ }^{\circ} \mathrm{C}$ for $30 \mathrm{~s}$, and $72{ }^{\circ} \mathrm{C}$ for $30 \mathrm{~s}$, last followed by one cycle of $95{ }^{\circ} \mathrm{C}$ for $1 \mathrm{~min}, 58^{\circ} \mathrm{C}$ for $30 \mathrm{~s}$, and $95^{\circ} \mathrm{C}$ for $30 \mathrm{~s}$. Results are based on cycle threshold $(\mathrm{Ct})$ values. We calculated differences between the $\mathrm{Ct}$ values for experimental and reference (GAPDH) gene and graphed the results as the ratio of each RNA to the calibrated sample (mature EC, HCEC). Primers used for gene amplification are shown in Supporting Information Table S1. 


\section{Preparation of LXW7 Modified Biomaterial Scaffolds}

Fabrication of electrospun microfibrous biomaterial scaffolds was performed as previously reported. ${ }^{15,59,60}$ Poly(L-lactic acid; PLLA; MW 67 400, Sigma-Aldrich) and polycaprolactone (PCL, MW 2000, Polysciences) were used to fabricate the microfibrous membranes. The polymer blends (e.g., 19\% PLLA and 5\% PCL; w/v) were completely dissolved in 1,1,1,3,3,3-hexafluoro-2-propanol (HFIP, Aladdin). Microfibrous membranes with a thickness of about $200 \mu \mathrm{m}$ were prepared by electrospinning polymer fibers onto the rotating drum collector. The negative voltage of $4.5 \mathrm{kV}$ was applied to the mandrel, and a positive voltage of $4 \mathrm{kV}$ was applied to the spinneret by using a high voltage generator (Gamma High Voltage).

LXW7 was grafted onto the PLLA/PCL membrane surface through three steps. First, membranes were incubated in $0.01 \mathrm{M}$ sodium hydroxide for $10 \mathrm{~min}$ to expose the carboxyl groups on the surface. Second, the membranes were further incubated in a solution of 1ethyl-3-(3-(dimethylamino)propyl) carbodiimide hydrochloride (EDC) and $\mathrm{N}$ hydroxysulfosuccinimide (sulfo-NHS; Thermo Fisher Scientific) in $0.5 \mathrm{M}$ morpholino ethanesulfonic acid (MES) buffer (pH 5.5, Thermo Fisher Scientific) for $30 \mathrm{~min}$. After brief washing with DPBS, the membranes were incubated in a solution of $\mathrm{H}_{2} \mathrm{~N}$-PEG-alkyne (MP 5000 , Polysciences, Inc.) in DPBS for $2 \mathrm{~h}$ on a shaker. Last, $100 \mathrm{nM}$ azido derivatized LXW7 (LXW7-N 3 ; Figure 7B), synthesized via a similar approach to that for LXW7-bio but with a 5-azidopentanoic acid attached to the side chain of lysine (Supporting Information Figure S1), was conjugated to alkyne-decorated membranes via Click chemistry in the presence of $5 \mu \mathrm{M} \mathrm{CuSO}_{4} \cdot 5 \mathrm{H}_{2} \mathrm{O}, 50 \mu \mathrm{M}$ sodium ascorbate, $\mathrm{Cu}$ powder, and $N, N$ diisopropyle-thylamine (DIEA; all from Sigma) in a water system for 6 days. ${ }^{82}$

The structure of the membranes was characterized with a scanning electron microscope (SEM, Hitachi TM-1000). Attenuated total reflection spectra of the untreated, PEG only modified, and PEG-LXW7 modified membranes were obtained using an attenuated total reflectance-Fourier transform infrared (ATR-FTIR) spectrometer (PerkinElmer).

\section{Biomaterial Scaffold Modified with LXW7 Supported EC Attachment and Spreading}

LXW7 modified electrospun microfibrous membranes and untreated control membranes were placed in $35 \mathrm{~mm}$ tissue culture dishes. The membranes were rinsed with DPBS and incubated with HCECs in EGM-2 media at a density of $5 \times 10^{4}$ cells $/ \mathrm{cm}^{2}$. After $2 \mathrm{~h}$ of incubation, the media was aspirated, and unattached cells were washed off with DPBS three times. The adhered cells were fixed in $10 \%$ formalin and incubated overnight with mouse anti-CD31 antibody (1:100; Abcam) at $4{ }^{\circ} \mathrm{C}$. After being washed, the adhered cells were incubated with goat antimouse Alexa Fluor 594 conjugate (1:500; Life Technologies) for $1 \mathrm{~h}$ at RT, and then nuclei were stained with DAPI. After three washings with DPBS, the cells were imaged using an Olympus IX81 microscope. Some of the cell samples were further cultured in EGM-2 media for 2 days, and cell morphology and spreading on the microfibrous scaffold surface were characterized with SEM. The cell-covered area was quantified using ImageJ software. 


\section{Statistical Analysis}

For two-sample comparison, a Student's $t$ test was used. For multiple-sample comparison, analysis of variance (ANOVA) was performed to detect whether a significant difference existed between groups with different treatments, and Tukey's multiple comparisons test was used for postanalysis. A $p$ value of 0.05 or less indicates a significant difference between samples in comparison.

\section{Supplementary Material}

Refer to Web version on PubMed Central for supplementary material.

\section{Acknowledgments}

The authors would like to thank G. Sun and Y. Si from UC Davis Textiles and Clothing for analyzing the material surface using the ATR-FTIR spectrometer and E. Silva from UC Davis Department of Biomedical Engineering for scientific discussion in isolating endothelial colony forming cells from cord blood. The authors would also like to thank C.-X. Pan from UC Davis Medical Center for providing platelet-rich plasma. This work was supported by the National Natural Science Foundation of China grant no. 81273417 and no. 31470939 and Shandong Province Taishan Scholar Pharmacy funding no. 21310004011253, the UC Davis Medical Center Interdepartmental Seed Grant, UC Davis Medical Center for Biophotonics (C4B) Pilot Grant, and the Science Translation and Innovative Research (STAIR) grant offered by UC Davis Venture Catalyst. The authors would also like to thank the Combinatorial Chemistry Shared Resource at University of California Davis for assistance with design and synthesis of peptides and their derivatives as well as on-bead cell binding assay. Utilization of this Shared Resource was supported by the UC Davis Comprehensive Cancer Center Support Grant (NCI P30CA093373).

\section{References}

1. Langer R. Tissue engineering. Mol Ther. 2000; 1:12-15. [PubMed: 10933907]

2. Langer R, Vacanti JP. Tissue engineering. Science. 1993; 260:920-926. [PubMed: 8493529]

3. Carmeliet P, Jain RK. Molecular mechanisms and clinical applications of angiogenesis. Nature. 2011; 473:298-307. [PubMed: 21593862]

4. Yoder MC, Ingram DA. Endothelial progenitor cell: ongoing controversy for defining these cells and their role in neoangiogenesis in the murine system. Curr Opin Hematol. 2009; 16:269-273. [PubMed: 19417649]

5. Santos MI, Reis RL. Vascularization in bone tissue engineering: physiology, current strategies, major hurdles and future challenges. Macromol Biosci. 2010; 10:12-27. [PubMed: 19688722]

6. Frantz C, Stewart KM, Weaver VM. The extracellular matrix at a glance. J Cell Sci. 2010; 123:4195-4200. [PubMed: 21123617]

7. Hynes RO. The extracellular matrix: not just pretty fibrils. Science. 2009; 326:1216-1219. [PubMed: 19965464]

8. Gong Z, Niklason LE. Blood vessels engineered from human cells. Trends Cardiovasc Med. 2006; 16:153-156. [PubMed: 16781948]

9. Zhang WJ, Liu W, Cui L, Cao Y. Tissue engineering of blood vessel. J Cell Mol Med. 2007; 11:945-957. [PubMed: 17979876]

10. Jordan SW, Chaikof EL. Novel thromboresistant materials. J Vasc Surg. 2007; 45(6):A104-A115. [PubMed: 17544031]

11. Rose SF, Lewis AL, Hanlon GW, Lloyd AW. Biological responses to cationically charged phosphorylcholine-based materials in vitro. Biomaterials. 2004; 25:5125-5135. [PubMed: 15109836]

12. Williams DF. On the mechanisms of biocompatibility. Biomaterials. 2008; 29:2941-2953. [PubMed: 18440630] 
13. He W, Ma Z, Yong T, Teo WE, Ramakrishna S. Fabrication of collagen-coated biodegradable polymer nano-fiber mesh and its potential for endothelial cells growth. Biomaterials. 2005; 26:7606-7615. [PubMed: 16000219]

14. Lee YB, Shin YM, Lee JH, Jun I, Kang JK, Park JC, Shin H. Polydopamine-mediated immobilization of multiple bioactive molecules for the development of functional vascular graft materials. Biomaterials. 2012; 33:8343-8352. [PubMed: 22917738]

15. Yu J, Wang A, Tang Z, Henry J, Li-Ping Lee B, Zhu Y, Yuan F, Huang F, Li S. The effect of stromal cell-derived factor-1alpha/heparin coating of biodegradable vascular grafts on the recruitment of both endothelial and smooth muscle progenitor cells for accelerated regeneration. Biomaterials. 2012; 33:8062-8074. [PubMed: 22884813]

16. Zeng W, Wen C, Wu Y, Li L, Zhou Z, Mi J, Chen W, Yang M, Hou C, Sun J, Zhu C. The use of BDNF to enhance the patency rate of small-diameter tissue-engineered blood vessels through stem cell homing mechanisms. Biomaterials. 2012; 33:473-484. [PubMed: 22000787]

17. Zeng W, Yuan W, Li L, Mi J, Xu S, Wen C, Zhou Z, Xiong J, Sun J, Ying D, Yang M, Li X, Zhu C. The promotion of endothelial progenitor cells recruitment by nerve growth factors in tissueengineered blood vessels. Biomaterials. 2010; 31:1636-1645. [PubMed: 20006381]

18. Zheng W, Wang Z, Song L, Zhao Q, Zhang J, Li D, Wang S, Han J, Zheng XL, Yang Z, Kong D. Endothelialization and patency of RGD-functionalized vascular grafts in a rabbit carotid artery model. Biomaterials. 2012; 33:2880-2891. [PubMed: 22244694]

19. Klinger MH, Jelkmann W. Role of blood platelets in infection and inflammation. J Interferon Cytokine Res. 2002; 22:913-922. [PubMed: 12396713]

20. Stokes KY, Granger DN. Platelets: a critical link between inflammation and microvascular dysfunction. J Physiol. 2012; 590:1023-1034. [PubMed: 22183721]

21. Wagner DD, Burger PC. Platelets in inflammation and thrombosis. Arterioscler, Thromb, Vasc Biol. 2003; 23:2131-2137. [PubMed: 14500287]

22. Qin Z. The use of THP-1 cells as a model for mimicking the function and regulation of monocytes and macrophages in the vasculature. Atherosclerosis. 2012; 221:2-11. [PubMed: 21978918]

23. Shi C, Pamer EG. Monocyte recruitment during infection and inflammation. Nat Rev Immunol. 2011; 11:762-774. [PubMed: 21984070]

24. Francis SE. Integrins and vascular development in differentiated embryonic stem cells in vitro. Methods Mol Biol. 2006; 330:331-340. [PubMed: 16846034]

25. Malinin NL, Pluskota E, Byzova TV. Integrin signaling in vascular function. Curr Opin Hematol. 2012; 19:206-211. [PubMed: 22488305]

26. Rupp PA, Little CD. Integrins in vascular development. Circ Res. 2001; 89:566-572. [PubMed: 11577021]

27. Caiado F, Dias S. Endothelial progenitor cells and integrins: adhesive needs. Fibrog Tissue Repair. 2012; 5:4.

28. Curley GP, Blum H, Humphries MJ. Integrin antagonists. Cell Mol Life Sci. 1999; 56:427-441. [PubMed: 11212296]

29. D'Souza SE, Ginsberg MH, Plow EF. Arginyl-glycyl-aspartic acid (RGD): a cell adhesion motif. Trends Biochem Sci. 1991; 16:246-250. [PubMed: 1926332]

30. Jin H, Varner J. Integrins: roles in cancer development and as treatment targets. Br J Cancer. 2004; 90:561-565. [PubMed: 14760364]

31. Ruoslahti E, Pierschbacher MD. Arg-Gly-Asp: a versatile cell recognition signal. Cell. 1986; 44:517-518. [PubMed: 2418980]

32. Brooks PC, Clark RA, Cheresh DA. Requirement of vascular integrin alpha v beta 3 for angiogenesis. Science. 1994; 264:569-571. [PubMed: 7512751]

33. Goodman SL, Holzemann G, Sulyok GA, Kessler H. Nanomolar small molecule inhibitors for alphav(beta)6, alphav(beta)5, and alphav(beta)3 integrins. J Med Chem. 2002; 45:1045-1051. [PubMed: 11855984]

34. Lam KS, Salmon SE, Hersh EM, Hruby VJ, Kazmierski WM, Knapp RJ. A new type of synthetic peptide library for identifying ligand-binding activity. Nature. 1991; 354:82-84. [PubMed: 1944576] 
35. Peng L, Liu R, Marik J, Wang X, Takada Y, Lam KS. Combinatorial chemistry identifies highaffinity peptidomimetics against alpha4beta1 integrin for in vivo tumor imaging. Nat Chem Biol. 2006; 2:381-389. [PubMed: 16767086]

36. Xiao W, Wang Y, Lau EY, Luo J, Yao N, Shi C, Meza L, Tseng H, Maeda Y, Kumaresan P, Liu R, Lightstone FC, Takada Y, Lam KS. The use of one-bead one-compound combinatorial library technology to discover high-affinity alphavbeta3 integrin and cancer targeting arginine-glycineaspartic acid ligands with a built-in handle. Mol Cancer Ther. 2010; 9:2714-2723. [PubMed: 20858725]

37. Yao N, Xiao W, Wang X, Marik J, Park SH, Takada Y, Lam KS. Discovery of targeting ligands for breast cancer cells using the one-bead one-compound combinatorial method. J Med Chem. 2009; 52:126-133. [PubMed: 19055415]

38. Dabiri BE, Lee H, Parker KK. A potential role for integrin signaling in mechanoelectrical feedback. Prog Biophys Mol Biol. 2012; 110:196-203. [PubMed: 22819851]

39. Barber TA, Ho JE, De Ranieri A, Virdi AS, Sumner DR, Healy KE. Peri-implant bone formation and implant integration strength of peptide-modified $\mathrm{p}$ (AAM-co-EG/AAC) interpenetrating polymer network-coated titanium implants. J Biomed Mater Res, Part A. 2007; 80:306-320.

40. Hynes RO. Integrins: bidirectional, allosteric signaling machines. Cell. 2002; 110:673-687. [PubMed: 12297042]

41. Rammelt S, Illert T, Bierbaum S, Scharnweber D, Zwipp H, Schneiders W. Coating of titanium implants with collagen, RGD peptide and chondroitin sulfate. Biomaterials. 2006; 27:5561-5571. [PubMed: 16879866]

42. Bennett JS. Structure and function of the platelet integrin alphaIIbbeta3. J Clin Invest. 2005; 115:3363-3369. [PubMed: 16322781]

43. Lefkovits J, Plow EF, Topol EJ, Epstein FH. Platelet glycoprotein IIb/IIIa receptors in cardiovascular medicine. N Engl J Med. 1995; 332:1553-1559. [PubMed: 7739710]

44. Olsson AK, Dimberg A, Kreuger J, Claesson-Welsh L. VEGF receptor signalling - in control of vascular function. Nat Rev Mol Cell Biol. 2006; 7:359-371. [PubMed: 16633338]

45. Soldi R, Mitola S, Strasly M, Defilippi P, Tarone G, Bussolino F. Role of alphavbeta3 integrin in the activation of vascular endothelial growth factor receptor-2. EMBO J. 1999; 18:882-892. [PubMed: 10022831]

46. Wang H, Luo X, Leighton J. Extracellular Matrix and Integrins in Embryonic Stem Cell Differentiation. Biochem Insights. 2015; 8:15-21. [PubMed: 26462244]

47. Maeng YS, Choi YJ, Kim EK. TGFBIp regulates differentiation of EPC (CD133(+) C-kit(+) Lin(-) cells) to EC through activation of the Notch signaling pathway. Stem Cells. 2015; 33:20522062. [PubMed: 25786978]

48. Scheppke L, Murphy EA, Zarpellon A, Hofmann JJ, Merkulova A, Shields DJ, Weis SM, Byzova TV, Ruggeri ZM, Iruela-Arispe ML, Cheresh DA. Notch promotes vascular maturation by inducing integrin-mediated smooth muscle cell adhesion to the endothelial basement membrane. Blood. 2012; 119:2149-2158. [PubMed: 22134168]

49. Wang N, Tytell JD, Ingber DE. Mechanotransduction at a distance: mechanically coupling the extracellular matrix with the nucleus. Nat Rev Mol Cell Biol. 2009; 10:75-82. [PubMed: 19197334]

50. Lin YS, Wang SS, Chung TW, Wang YH, Chiou SH, Hsu JJ, Chou NK, Hsieh KH, Chu SH. Growth of endothelial cells on different concentrations of Gly-Arg-Gly-Asp photochemically grafted in polyethylene glycol modified polyurethane. Artif Organs. 2001; 25:617-621. [PubMed: 11531712]

51. Berthiaume F, Maguire TJ, Yarmush ML. Tissue engineering and regenerative medicine: history, progress, and challenges. Annu Rev Chem Biomol Eng. 2011; 2:403-430. [PubMed: 22432625]

52. Lovett M, Lee K, Edwards A, Kaplan DL. Vascularization strategies for tissue engineering. Tissue Eng, Part B. 2009; 15:353-370.

53. Nomi M, Miyake H, Sugita Y, Fujisawa M, Soker S. Role of growth factors and endothelial cells in therapeutic angiogenesis and tissue engineering. Curr Stem Cell Res Ther. 2006; 1:333-343. [PubMed: 18220878] 
54. Urbich C, Dimmeler S. Endothelial progenitor cells: characterization and role in vascular biology. Circ Res. 2004; 95:343-353. [PubMed: 15321944]

55. Place ES, Evans ND, Stevens MM. Complexity in biomaterials for tissue engineering. Nat Mater. 2009; 8:457-470. [PubMed: 19458646]

56. Liu W, Thomopoulos S, Xia Y. Electrospun nanofibers for regenerative medicine. Adv Healthcare Mater. 2012; 1:10-25.

57. Ma PX. Biomimetic materials for tissue engineering. Adv Drug Delivery Rev. 2008; 60:184-198.

58. Wang X, Ding B, Li B. Biomimetic electrospun nanofibrous structures for tissue engineering. Mater Today. 2013; 16:229-241.

59. Wang A, Tang Z, Park IH, Zhu Y, Patel S, Daley GQ, Li S. Induced pluripotent stem cells for neural tissue engineering. Biomaterials. 2011; 32:5023-5032. [PubMed: 21514663]

60. Zhu Y, Wang A, Patel S, Kurpinski K, Diao E, Bao X, Kwong G, Young WL, Li S. Engineering bilayer nanofibrous conduits for peripheral nerve regeneration. Tissue Eng, Part C. 2011; 17:705715.

61. Downing TL, Wang A, Yan ZQ, Nout Y, Lee AL, Beattie MS, Bresnahan JC, Farmer DL, Li S. Drug-eluting microfibrous patches for the local delivery of rolipram in spinal cord repair. $\mathrm{J}$ Controlled Release. 2012; 161:910-917.

62. Saadai P, Nout YS, Encinas J, Wang A, Downing TL, Beattie MS, Bresnahan JC, Li S, Farmer DL. Prenatal repair of myelomeningocele with aligned nanofibrous scaffolds-a pilot study in sheep. J Pediatr Surg. 2011; 46:2279-2283. [PubMed: 22152865]

63. Saadai P, Wang A, Nout YS, Downing TL, Lofberg K, Beattie MS, Bresnahan JC, Li S, Farmer DL. Human induced pluripotent stem cell-derived neural crest stem cells integrate into the injured spinal cord in the fetal lamb model of myelomeningocele. J Pediatr Surg. 2013; 48:158-163. [PubMed: 23331809]

64. Zhu Y, Wang A, Shen W, Patel S, Zhang R, Young W, Li S. Nanofibrous Patches for Spinal Cord Regeneration. Adv Funct Mater. 2010; 20:1433-1440. [PubMed: 23378825]

65. Qi H, Hu P, Xu J, Wang A. Encapsulation of drug reservoirs in fibers by emulsion electrospinning: morphology characterization and preliminary release assessment. Biomacromolecules. 2006; 7:2327-2330. [PubMed: 16903678]

66. Lee BL, Jeon H, Wang A, Yan Z, Yu J, Grigoropoulos C, Li S. Femtosecond laser ablation enhances cell infiltration into three-dimensional electrospun scaffolds. Acta Biomater. 2012; 8:2648-2658. [PubMed: 22522128]

67. Ruoslahti E. RGD and other recognition sequences for integrins. Annu Rev Cell Dev Biol. 1996; 12:697-715. [PubMed: 8970741]

68. Aina $\mathrm{OH}$, Marik J, Gandour-Edwards R, Lam KS. Near-infrared optical imaging of ovarian cancer xenografts with novel alpha 3-integrin binding peptide "OA02". Mol Imaging. 2005; 4:439-447. [PubMed: 16285906]

69. Xiao W, Yao N, Peng L, Liu R, Lam KS. Near-infrared optical imaging in glioblastoma xenograft with ligand-targeting alpha 3 integrin. Eur J Nucl Med Mol Imaging. 2009; 36:94-103. [PubMed: 18712382]

70. Wang Z, Wang H, Zheng W, Zhang J, Zhao Q, Wang S, Yang Z, Kong D. Highly stable surface modifications of poly(3-caprolactone) (PCL) films by molecular self-assembly to promote cells adhesion and proliferation. Chem Commun. 2011; 47:8901-8903.

71. Woollard KJ, Geissmann F. Monocytes in atherosclerosis: subsets and functions. Nat Rev Cardiol. 2010; 7:77-86. [PubMed: 20065951]

72. de Fougerolles AR, Chi-Rosso G, Bajardi A, Gotwals P, Green CD, Koteliansky VE. Global expression analysis of extracellular matrix-integrin interactions in monocytes. Immunity. 2000; 13:749-758. [PubMed: 11163191]

73. Prieto J, Eklund A, Patarroyo M. Regulated Expression of Integrins and Other Adhesion Molecules during Differentiation of Monocytes into Macrophages. Cell Immunol. 1994; 156:191-211. [PubMed: 8200035]

74. Goodman SL. Sheep, pig, and human platelet-material interactions with model cardiovascular biomaterials. J Biomed Mater Res. 1999; 45:240-250. [PubMed: 10397982] 
75. Lee JH, Lee HB. Platelet adhesion onto wettability gradient surfaces in the absence and presence of plasma proteins. J Biomed Mater Res. 1998; 41:304-311. [PubMed: 9638536]

76. Reviakine I, Editor G, Braune S, Editor G. Preface: In Focus Issue on Blood-Biomaterial Interactions. Biointerphases. 2016; 11:029501. [PubMed: 27341991]

77. Somanath PR, Malinin NL, Byzova TV. Cooperation between integrin alphavbeta 3 and VEGFR2 in angio-genesis. Angiogenesis. 2009; 12:177-185. [PubMed: 19267251]

78. Wang Y, Xiao W, Zhang Y, Meza L, Tseng H, Takada Y, Ames JB, Lam KS. Optimization of RGD-Containing Cyclic Peptides against alphavbeta3 Integrin. Mol Cancer Ther. 2016; 15:232240. [PubMed: 26719578]

79. Peng L, Liu RW, Marik J, Wang XB, Takada Y, Lam KS. Combinatorial chemistry identifies highaffinity peptidomimetics against alpha(4)beta(1) integrin for in vivo tumor imaging. Nat Chem Biol. 2006; 2:381-389. [PubMed: 16767086]

80. Williams PA, Stilhano RS, To VP, Tran L, Wong K, Silva EA. Hypoxia augments outgrowth endothelial cell (OEC) sprouting and directed migration in response to sphingosine-1-phosphate (S1P). PLoS One. 2015; 10:e0123437. [PubMed: 25875493]

81. Ingram DA, Mead LE, Tanaka H, Meade V, Fenoglio A, Mortell K, Pollok K, Ferkowicz MJ, Gilley D, Yoder MC. Identification of a novel hierarchy of endothelial progenitor cells using human peripheral and umbilical cord blood. Blood. 2004; 104:2752-2760. [PubMed: 15226175]

82. Nandivada H, Chen HY, Bondarenko L, Lahann J. Reactive polymer coatings that "Click". Angew Chem, Int Ed. 2006; 45:3360-3363. 


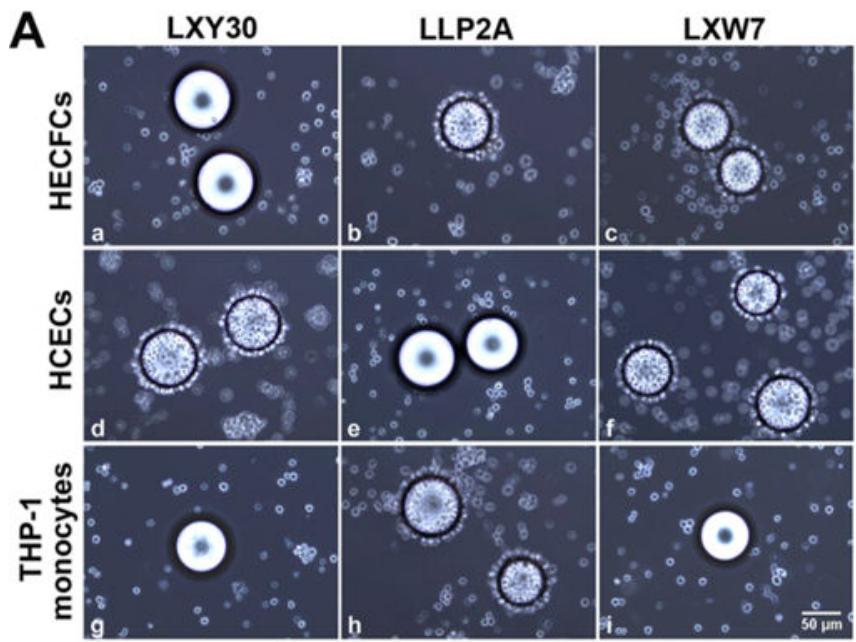

B

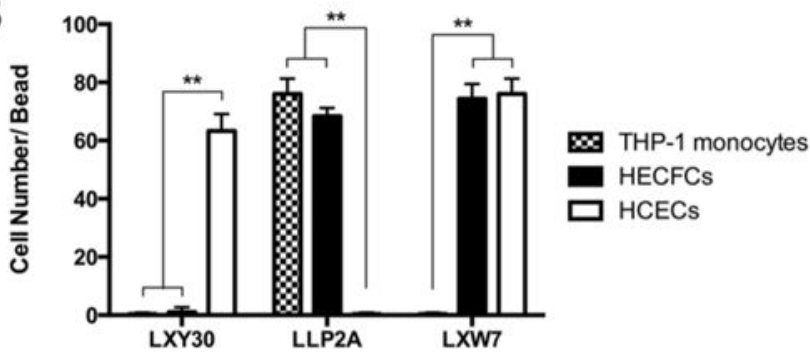

Figure 1.

On-bead cell binding assay for testing EPC/EC binding affinity of ligands. (A) HECFCs (ac), HCECs ( $\mathrm{d}-\mathrm{f})$, and THP-1 monocytes ( $\mathrm{g}-\mathrm{i})$ were incubated with resin beads displaying LXY30 (left panels), LLP2A (middle panels), and LXW7 (right panels). Scale bar $=50 \mu \mathrm{m}$. (B) The number of cells bound on beads displaying different types of ligands were quantified, and statistical analyses were performed. Data were expressed as mean \pm standard deviation: $* * p<0.01(n=3)$. 

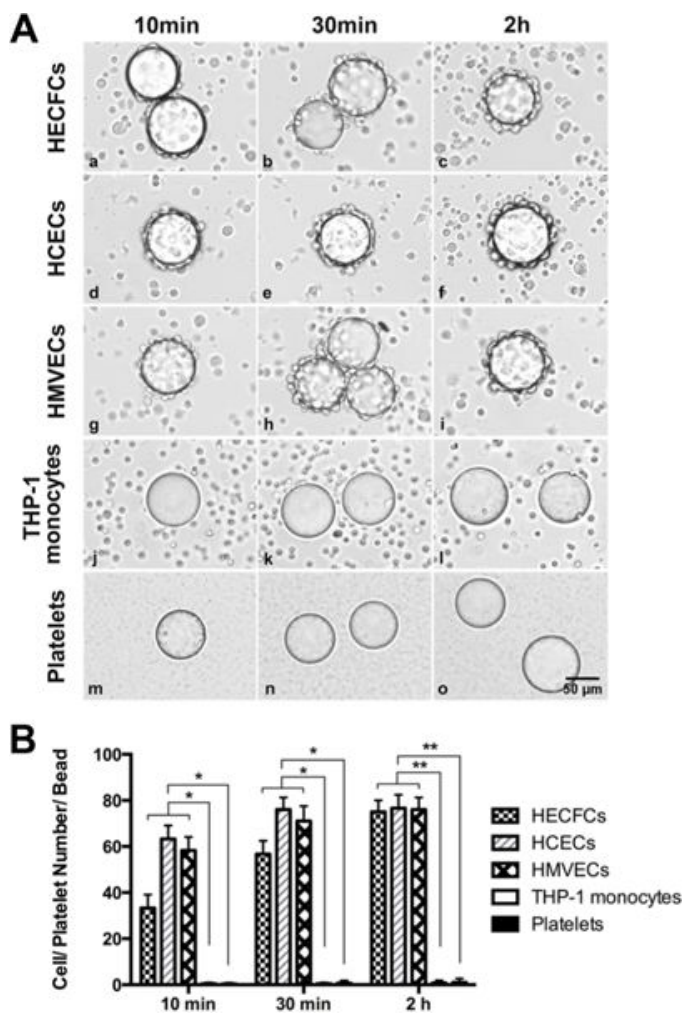

Figure 2.

Binding specificity of LXW7 to EPCs/ECs. (A) Beads displaying LXW7 were incubated with HECFCs $(a-c)$, HCECs (d-f), HMVECs $(g-i)$, THP-1 monocytes $(j-1)$, or platelets (mo) for $10 \mathrm{~min}$ (left panels), $30 \mathrm{~min}$ (middle panels), or $2 \mathrm{~h}$ (right panels). LXW7 efficiently supported EPC/EC attachment (a-i) but did not support effective attachment of THP-1 monocytes $(\mathrm{j}-\mathrm{l})$, or platelets $(\mathrm{m}-\mathrm{o})$. Scale bar $=50 \mu \mathrm{m}$. (B) The numbers of different types of cells bound on each bead displaying LXW7 were quantified, and statistical analyses were performed. Data were expressed as mean \pm standard deviation: $* p<0.05$, ** $p<0.01(n=$ 3). 

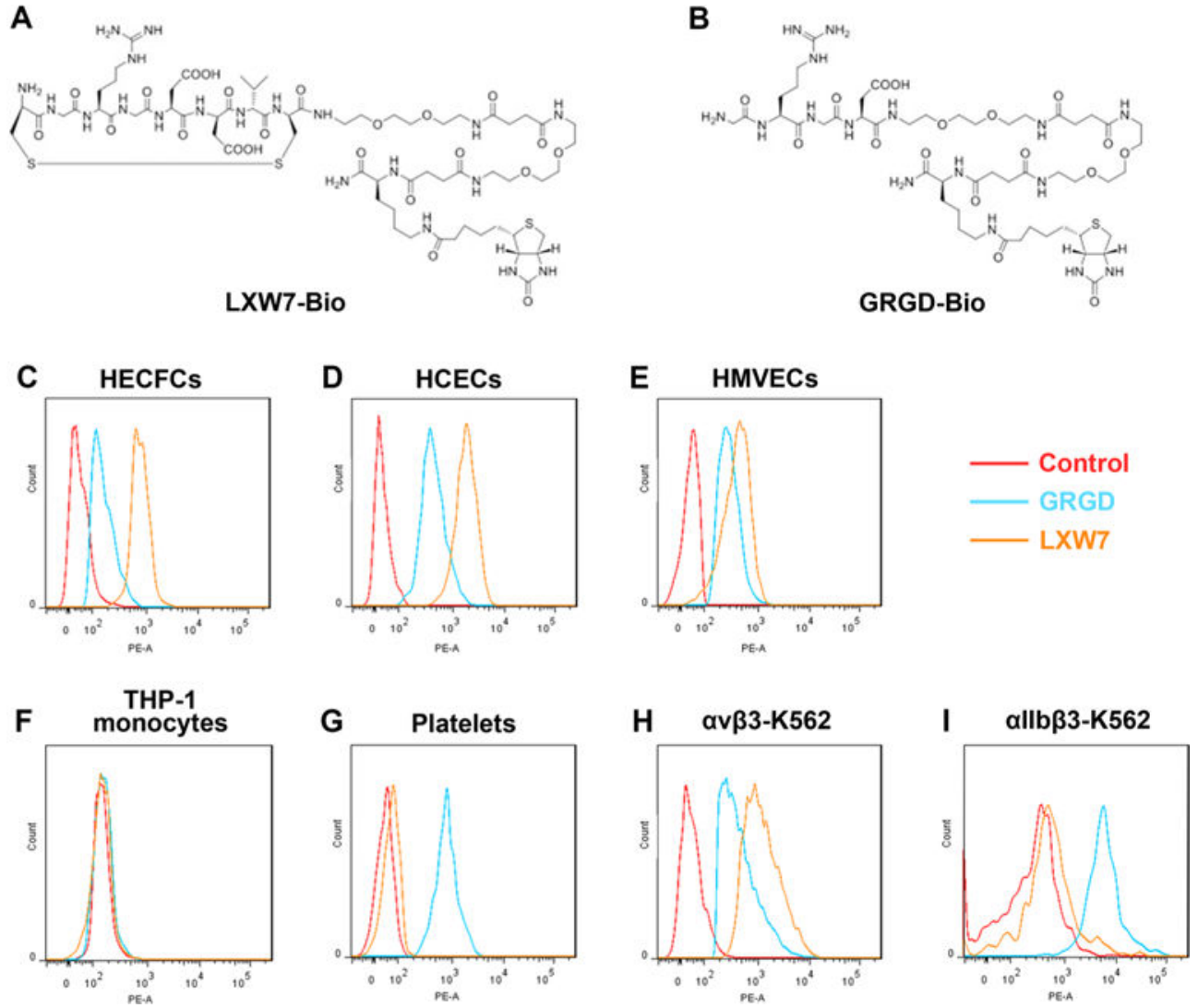

Figure 3.

Binding affinity of LXW7 and GRGD to different cell types tested by flow cytometry. The structures of LXW7-Bio (A) and GRGD-Bio (B). EPCs and ECs from different sources including HECFCs (C), HCECs (D), HMVECs (E), and THP-1 monocytes (F), platelets (G), and $\mathrm{K} 562$ cells engineered to highly express $a \mathrm{v} \beta 3($ av $\beta 3-\mathrm{K} 562, \mathrm{H})$ and $a \mathrm{IIb} \beta 3$ ( $a \mathrm{IIb} \beta 3$ K562, I) cells were incubated with the LXW7-bio, GRGD-bio, or D-biotin peptide and subsequently incubated with streptavidin-phycoerythrin. Flow cytometry analysis was performed to determine the binding affinity of the ligands. Samples treated with D-biotin were used as negative controls. 

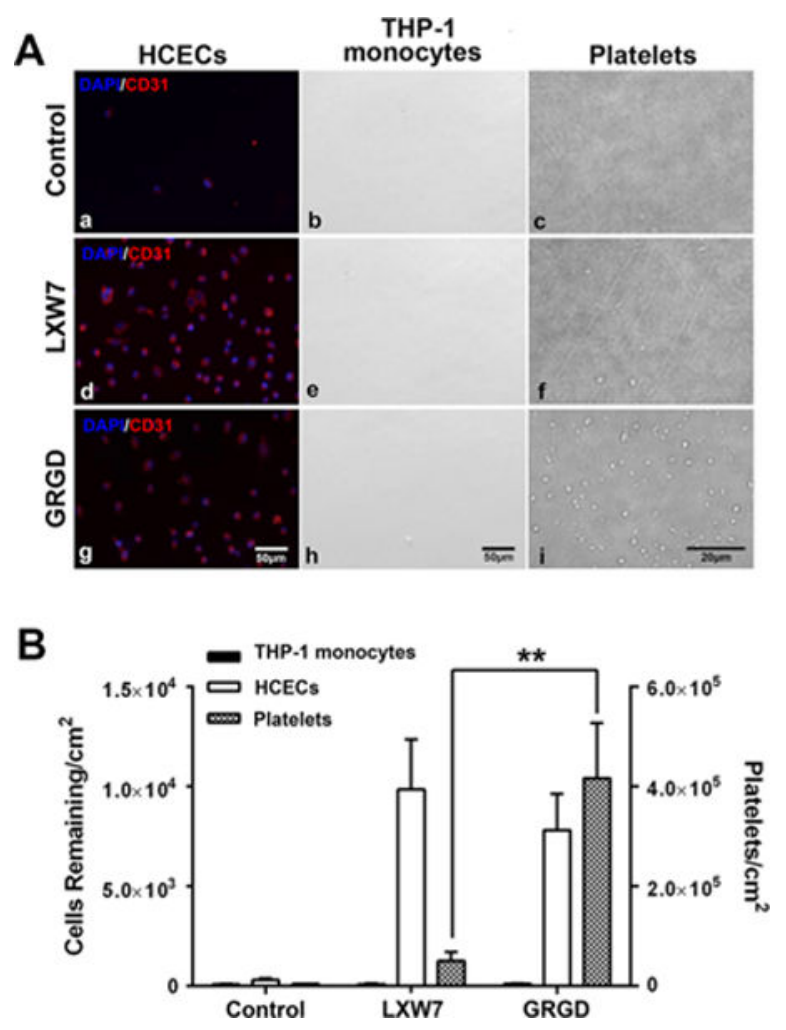

Figure 4.

Attachment of cells and platelets to LXW7 and GRGD treated surfaces. (A) Images of attached HCECs (left panels), THP-1 monocytes (middle panels), and platelets (right panels) on surfaces treated by D-biotin (a-c; control), LXW7 (d-f), or GRGD (g-i). Surfaces treated with D-biotin serving as the negative control. Scale bars in a, b, d, e, g, and h are $50 \mu \mathrm{m}$.

Scale bars in c, $\mathrm{f}$, and i are $20 \mu \mathrm{m}$. (B) The number of cells or platelets attached on different treated surfaces were quantified, and statistical analyses were performed. Data were expressed as mean \pm standard deviation: $* * p<0.01(n=4)$. 

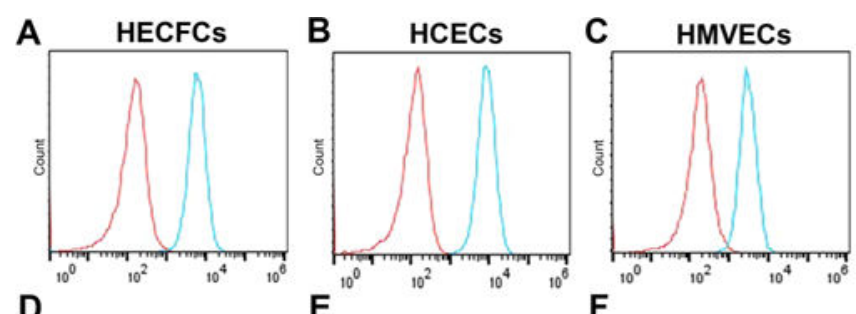

- Control
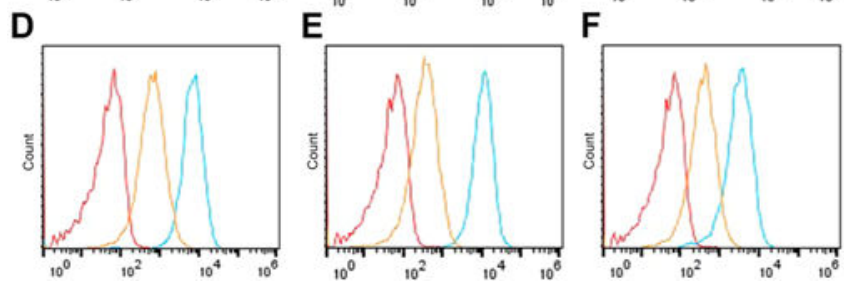

- Anti- $\alpha v \beta 3$

Figure 5.

Binding of LXW7 to EPCs and ECs was blocked by an anti-av $\beta 3$ integrin antibody. A mouse monoclonal anti- $a v \beta 3$ integrin antibody specifically bound to HECFCs (A, 99.0\%), HCECs (B, 100\%), and HMVECs (C, 97.3\%) indicating that EPCs and ECs express a high level of $a v \beta 3$ integrin. LXW7 bound effectively to all of the EPCs and ECs (blue curve in $\mathrm{D}-\mathrm{F}$ ), and the binding was markedly blocked by the anti- $a \mathrm{v} \beta 3$ integrin antibody at 20 $\mu \mathrm{g} / \mathrm{mL}$ (orange curve in $\mathrm{D}-\mathrm{F}$ ). 
A

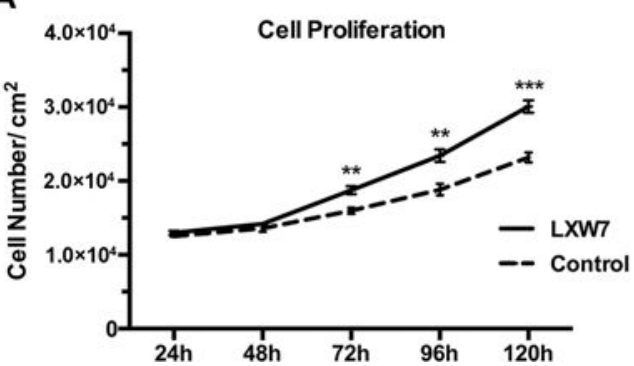

B

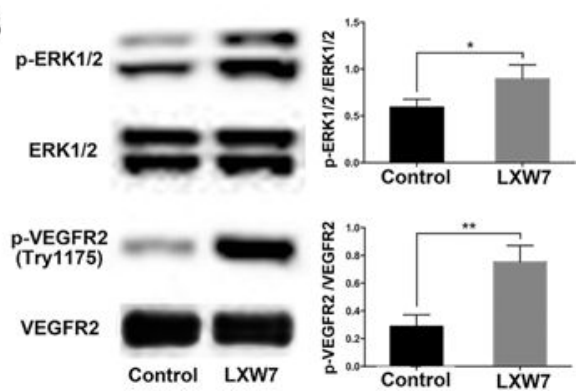

Figure 6.

Effects of LXW7 on EC biological functions. (A) Proliferation of ECs on LXW7 treated surfaces and the D-biotin treated surface (control) was assessed by MTS assay. Data were expressed as mean \pm standard deviation: ${ }^{* *} p<0.01,{ }^{* * *} p<0.001(n=4)$. (B) Western-blot analysis of the effect of LXW7 on phosphorylation of VEGFR2 (Tyr1175) and phosphorylation of ERK1/2 (left panels) and quantified by densitometry (right panels). Data were expressed as mean \pm standard deviation: ${ }^{*} p<0.05,{ }^{*} p<0.01(n=4)$. 
A

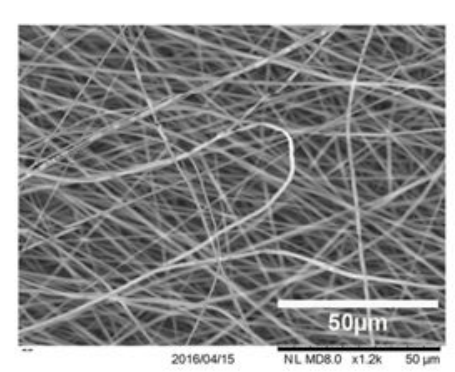

C

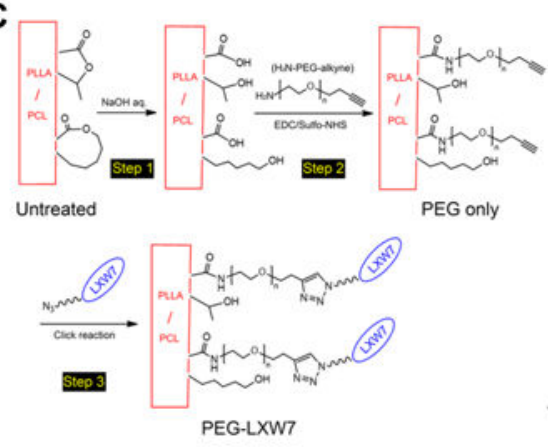

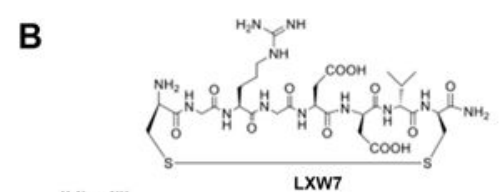

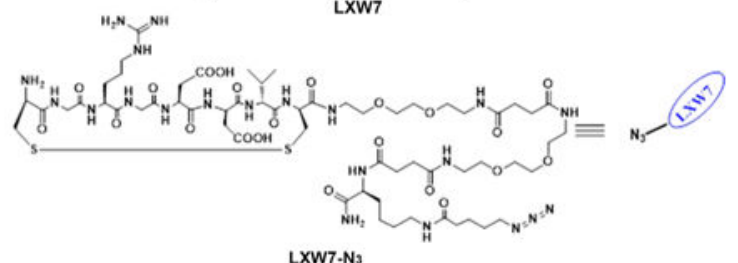

LXW7-N3

D

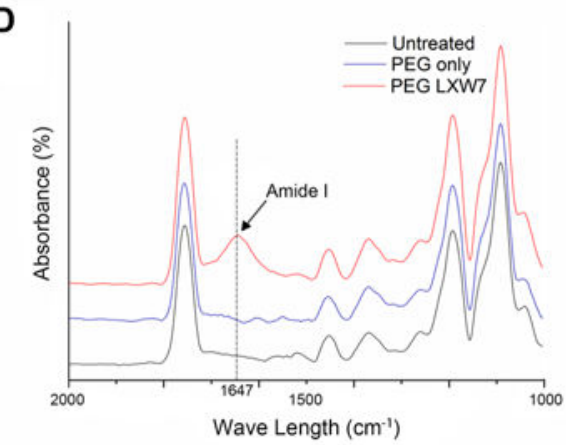

Figure 7.

Analysis of the microfibrous scaffold modified with LXW7 by Click chemistry. (A) The SEM analysis of the structure of electrospun microfibrous membrane. (B) The chemical structure of LXW7 and LXW7-N3. (C) Schematic of the chemical process involved in the linking of LXW7 to the electrospun microfibrous scaffold surface. (D) ATR-FTIR spectra of membranes with untreated (black line), PEG only modification (blue line), and PEG-LXW7 modification (red line). 
A

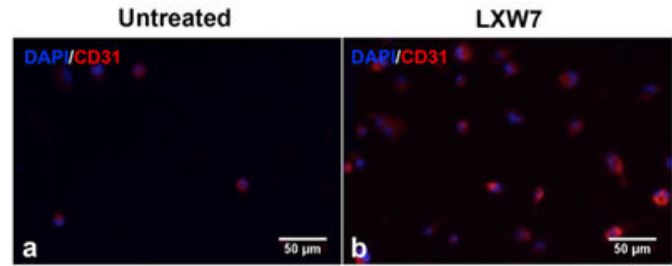

C

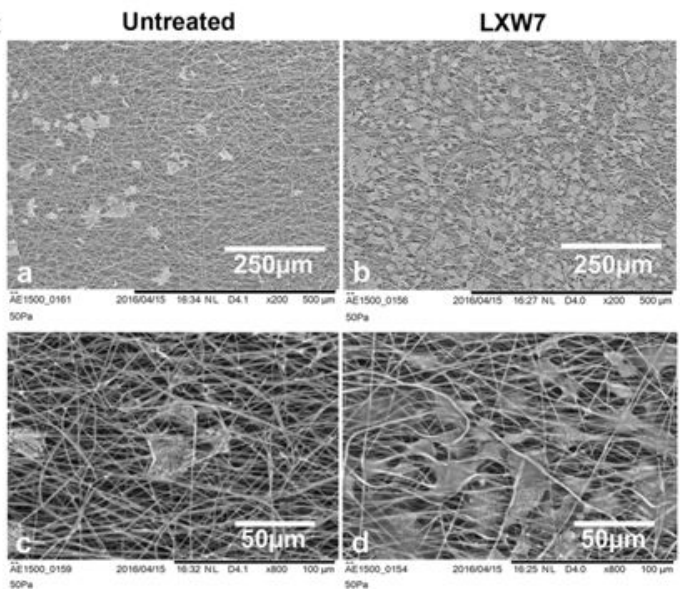

B

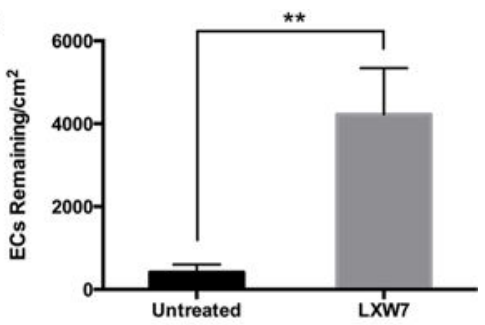

D

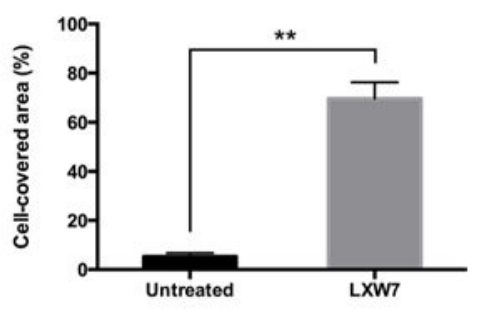

Figure 8.

Adherence of ECs to LXW7 modified nanofibrous membrane surface. (A) Representative immunocytochemistry images of CD31 stained HCECs adhered on untreated nanofibrous membrane surface (a) and LXW7-modified nanofibrous membrane surface (b) after $2 \mathrm{~h}$ incubation. Scale bar $=50 \mu \mathrm{m}$. (B) Quantification and the correlative statistical analysis of adhered cells from the CD31 immunostaining images. Data were expressed as mean \pm standard deviation: $* * p<0.01(n=3)$. (C) SEM images of ECs grown on an untreated membrane surface (a, c) and LXW7-modified nanofibrous membrane surface (b, d) for 2 days (scale bars in a, b: $250 \mu \mathrm{m}$; c, d: $50 \mu \mathrm{m}$ ). (D) Quantification and the correlative statistical analysis of cell-covered area from the SEM images. Data were expressed as mean \pm standard deviation: $* * p<0.01(n=3)$. 